\title{
nature
}

20 September 2001 Volume 413 Issue no 6853

\section{Fighting against terrorism, engaging with Islamic science}

Last week's attacks in New York and Washington were an offence against fundamental values that merits a well-targeted response, helped by science. But enhanced contacts with Islamic colleagues should also be pursued.

A s Nature goes to press, the world is wondering how President George W. Bush, given extra powers by Congress and significant support by other nations, will respond to the barbaric killings of thousands in the United States. The impact on the scientific community has already begun to make itself felt (see page 237). Leaders of the scientific community around the world have expressed their horror and sympathy: see http://www.nationalacademies.org.

Science itself will play a critical role in the identification of the victims and in the unprecedented intelligence and military steps that the United States and others will now take to prevent such attacks in the future (see page 238). Many of the finest scientists and engineers will be called upon to channel their expertise into the defence of their countries against repetitions of last week's atrocity, and against its perpetrators and their defenders in every corner of the globe.

Appropriately, given last week's offence against fundamental values, most are likely to respond in full measure. A previous generation of scientists quietly helped to assure victory for the Allies in the Second World War, through the development of radar, code-breaking algorithms, and the Manhattan Project to develop the atomic bomb (the last of which, as things turned out, had the least strategic significance of the three in that conflict). This time, the challenges lie in security innovations and counter-terrorism, intelligence gathering, and enhancing an already large military advantage.

\section{Science's role}

But scientists, and others engaged with science, can do more. Last week's terrible events are utterly removed from normal relations between countries and peoples. But they are not divorced from underlying political and social forces that also affect those relations. Perhaps the least to be expected of those in a position to make a difference is some reflection on the roles of science in the cultures and societies caught up in this conflict. How might contacts between scientists and between scientific organizations, of a sort that proved valuable during the cold war, play a constructive role in long-term relations?

With thousands of dead still to be identified and put to rest, engagement of any sort will be the last thing on many people's minds. But others, deeply affected by the conflict, may feel that not to explore it could be seen as a minor victory for terrorism.

Last week's terrorist violence, after all, was not the expression of a clash of civilizations: many Islamic scholars and leaders have emphasized that the murder of the innocent is as offensive to their beliefs as to anyone else's. Their societies should not stand condemned because of extremists who disagree.

Although there could be said to be a tide of Islamic activism in the Arabic world and in Asia, there is no uniformity about it. There is a common aspect, according to knowledgeable commentators, in which resurgent Islam appears to be giving a sense of values and cultural identity to populations that may see themselves as disadvantaged or repressed within their countries. But the political contexts and the consequences that follow are diverse - for example, only some activist groups are revolutionary in intent. Understanding that heterogeneity will be important.

\section{View s of the Enlightenment}

Differences in world view between most Western scientists and influential Islamic intellectuals (including scientists) can be profound. Societies in which Islamic beliefs are important include those actively importing Western science and technology, yet which have a distrust of the modernity and secularism of the West. Iranian political commentators, for example, saw the collapse of the Soviet system not as a triumph of the West but as a prelude to the total collapse of a system based on humanist beliefs fostered in the Western Enlightenment, which, in their eyes, committed the fatal error of divorcing a scientific understanding of nature from an appreciation of its divine aspects (see, for example, http://web.syr.edu/ mborouje/jpr.html). Most Western scientists, and this journal too, would consider a denial of Enlightenment values as a betrayal of everything science stands for.

In Iran and in other Islamic countries, there is no shortage of intellectual interest in the Western scientific and philosophical traditions. But questioning about the philosophical and spiritual underpinning of science can be intense. Whether only parts of Western science and culture can be imported, and whether secularization is an essential corollary of the Western Enlightenment, are important questions for Islamic scholars.

The scientist-turned-Islamic-scholar Seyyid Hossein Nasr has commented on divergent views about modern science within the Islamic world. One view, which he characterizes as 'modernist', has for over a century set about importing science without much attention to the consequences for the societies that seek to absorb it. Another view sees Western science as giving rise to ethical problems for Islam, but welcomes it nevertheless on the basis that Islam can resolve those challenges on its own ethical terms. And then there is Nasr's own view, which has been influential, and which sees science as inextricably bound up in the system of values in which it operates. It makes sense, in his terms, to identify Islamic science as related to Western science but "totally transformed into the part and parcel of the Islamic intellectual citadel” (see http://web.mit.edu/mitmsa/ www/NewSite/libstuff/nasr/nasrspeech1.html).

Evidently, in comparison with the character of cold-war contacts, there may well be fewer common assumptions between scientific communities in the West and those in Islamic countries. There is much less knowledge of each others' scientific histories, and a consequent lack of mutual appreciation. But both inside and outside the Islamic world, there is also room for consideration of shared beliefs about the values of science, its history and its significance. Funding agencies should foster collaborations between Islamic and Western scientists and between those in the humanities studying science. Now may be a particularly good time to do so. 